\title{
Author Correction: Acromegaly
}

Annamaria Colao, Ludovica F. S. Grasso, Andrea Giustina, Shlomo Melmed, Philippe Chanson, Alberto M. Pereira and Rosario Pivonello

Nature Reviews Disease Primers 5, Article number: 20 (2019) https://doi.org/10.1038/s41572-019-0071-6 Published online 21 March 2019

In the originally published version of Figure 1, the date for the regulatory approval of long-acting octreotide was incorrectly stated as 2004 , whereas the correct date is 1998. The corrected figure has now been added to the HTML and PDF versions of the article.

https://doi.org/10.1038/s41572-019-0129-5 I Published online: 21 October 2019 